\title{
Chronic Restraint Stress Decreases the Excitability of Hypothalamic POMC Neuron and Increases Food Intake
}

\author{
Go Eun Ha and Eunji Cheong* \\ Department of Biotechnology, College of Life Science and Biotechnology, Yonsei University, Seoul 03722, Korea
}

\begin{abstract}
Stress activates the hypothalamic-pituitary-adrenal system, and induces the release of glucocorticoids, stress hormones, into circulation. Many studies have shown that stress affects feeding behavior, however, the underlying circuitry and molecular mechanisms are not fully understood. The balance between orexigenic (simulating appetite) and anorexigenic (loss of appetite) signals reciprocally modulate feeding behavior. It is suggested that proopiomelanocortin (POMC) and neuropeptide Y (NPY) neurons in the arcuate nucleus (ARC) of the hypothalamus are the first-order neurons that respond to the circulating signals of hunger and satiety. Here, we examined a chronic restraint stress model and observed an increase in food intake, which was not correlated with anhedonia. We investigated whether stress affects the properties of POMC and NPY neurons and found that chronic restraint stress reduced the excitatory inputs onto POMC neurons and increased the action potential threshold. Therefore, our study suggests that chronic stress modulates the intrinsic excitability and excitatory inputs in POMC neurons, leading to changes in feeding behavior.
\end{abstract}

Key words: Stress response, Hypothalamus, Arcuate nucleus, Food intake, POMC

\section{INTRODUCTION}

As stress affects the hypothalamic-pituitary-adrenal (HPA) axis, which regulates the release of the stress hormones, cortisol in humans and corticosterone in rodents, which regulates many body processes, including digestion, the immune system, mood, and energy balance. The paraventricular nucleus $(\mathrm{PVN})$ of the hypothalamus, a key element of the HPA axis, has neuroendocrine neurons responsible for synthesizing and secreting corticotropinreleasing hormone $(\mathrm{CRH})$. The release of $\mathrm{CRH}$ to the anterior lobe of the pituitary gland stimulates the secretion of adrenocorticotropic hormone, which in turn activates the adrenal cortex, thereby producing and releasing stress hormones. The increase in stress hormones acts on the negative feedback to the hypothalamus and pituitary gland to inhibit the production of $\mathrm{CRH}$ and $\mathrm{ACTH}$,

Submitted November 2, 2021, Revised December 8, 2021,

Accepted December 11,2021

* To whom correspondence should be addressed.

TEL: 82-2-2123-5885, FAX: 82-2-362-7265

e-mail: eunjicheong@yonsei.ac.kr which in turn acts on the wide brain regions [1].

Stress hormones bind to the glucocorticoid receptors (GRs) and mineralocorticoid receptors (MRs), which are expressed in various brain regions, such as the septum, hippocampus, amygdala, and hypothalamus [2-4]. The hypothalamus plays an essential role in maintaining the homeostasis involving body temperature, hunger, thirst, sleep, and circadian rhythms. Glucocorticoids presumably affect feeding behavior via acting on the GRs that are abundantly expressed in the hypothalamus, particularly in the PVN and the arcuate nucleus (ARC) [2]. In human studies, an excess of glucocorticoids induces obesity, whereas its depletion causes anorexia $[5,6]$. Intracerebroventricular injection of glucocorticoids in rats induced an increase in food intake and a decrease in energy expenditure [7]. Indeed, stress has also been suggested to affect food intake. In human studies, exposure to laboratory stressors or selfreported stress causes either an increase or decrease in food intake [8-11]. In addition, some patients with major and atypical depressive disorder have symptoms such as overeating (hyperphagia) and food addiction [12-14]. Contrary to human studies, many animal studies reported that rodents exposed to acute or chronic stressors exhibited decreased food intake [15-17]. Therefore, the effects of 
stress on eating behaviors along with its molecular and circuitry mechanism is not fully understood.

The ARC within the hypothalamus is critical for the regulation of feeding and energy expenditure [18]. There are two types of neurons in the ARC: The orexigenic agouti-related peptide (AgRP) and neuropeptide Y (NPY)-expressing AgRP/NPY neurons and the anorexigenic pro-opiomelanocortin (POMC)-expressing POMC neurons $[19,20]$. They are thought of as "first-order neurons" that respond to the circulating peptides of hunger (ghrelin) and satiety (insulin, leptin, and so on) [21]. The activation of AgRP/NPY neurons markedly induces feeding and reduces energy expenditure [22]. POMC neurons inhibit feeding behavior by releasing melanocyte-stimulating hormones (MSH) that act on "second-order neurons" in the PVN, the dorsomedial hypothalamus (DMH), the lateral hypothalamus ( $\mathrm{LH})$, and the ventromedial hypothalamus (VMH), followed by projection to other brain regions related to energy intake and expenditure [23]. AgRP/NPY neurons also project to the "second-order neurons" in the PVN and $\mathrm{LH}$, and POMC neurons to inhibit neuronal activity by the release of GABA, AgRP, and NPY [24].

Here, we found that mice exposed to chronic restraint stress showed an increase in food intake independent of anhedonia. Using this rodent model, we examined the effect of chronic stress on the anorexigenic and orexigenic neurons, POMC and NPY neurons, respectively. Our study suggests that chronic restraint stress increased food intake and decreased excitability of POMC neurons.

\section{MATERIALS AND METHODS}

\section{Animals}

Wild-type C57BL/6J mice, POMC-eGFP mice (stock no. 009593), and AgRP/NPY-hrGFP mice (stock no. 006417) were housed in groups of $4 \sim 5$ per cage under a 12-hour light/dark cycle (lights on at $7 \mathrm{am})$ with a temperature $\left(22 \pm 2^{\circ} \mathrm{C}\right)$ and humiditycontrolled environment. The mice had ad libitum access to water and standard food pellets. All experiments were conducted according to the guidelines of the Institutional Animal Care and Use Committee at Yonsei University (Seoul, Korea).

\section{Chronic stressed models}

The experiments were performed after the animals had habituated to the experimental environment for more than 1 week. To investigate the effects of chronic stress, the experimental protocol for the animal model was designed based on well-established stress models from previous studies [25]. The timeline for the stressed models is presented in Fig. 1A. Male mice (8 9 weeks old) were di- vided into two groups: control (CON) and chronic restraint stress (CRS). The CRS mice were exposed daily to $6 \mathrm{~h}$ of restraint stress with a triangle-shaped plastic bag (custom-made) for 21 consecutive days (day 8 28). Restraint stress was conducted between 9 am and $3 \mathrm{pm}$.

\section{Behavioral procedures}

After the stressed procedure, C57BL/6J male mice were used for behavioral tests. Behavioral procedures were conducted in the light cycle except for the sucrose preference test, which was carried out for $21 \mathrm{~h}$ ( 3 pm to $9 \mathrm{am}$ ). Body weight was measured weekly before restraint stress in the CRS group. For the sucrose preference test, mice were habituated to single housing and drinking from two bottles containing water 1 day before the test (day 27). Mice had free access to food, water, and $1 \%$ sucrose solution during the sucrose preference test from 3 pm on day 28 to 9 am on day 29 . Food, water, and sucrose intake was measured, and the preference for sucrose was calculated by dividing the weight of sucrose intake consumed by the total weight of both water and sucrose intake. CON mice were deprived for $6 \mathrm{~h}$ before the sucrose preference test to provide the same conditions as the stressed mice. For the open field test, mice were placed in open-field arenas $(40 \times 40 \times 40$ $\mathrm{cm}$; length $\times$ width $\times$ height) for $60 \mathrm{~min}$ at 30 lux of light intensity to assess general locomotor activity and anxiety. The movement of mice was recorded and analyzed using a video tracking software EthoVision (Noldus Information Technology, Leesburg, VA, USA). The total distance travelled and the time spent in the center were recorded. The distance traveled was also analyzed at $5 \mathrm{~min}$ time intervals. For the light dark test, the light-dark box consisted of two chambers, one box $(20 \times 20 \times 20 \mathrm{~cm})$ being exposed to the light without a ceiling while the other $(20 \times 13 \times 20 \mathrm{~cm})$ covered with black ceiling and walls. The light intensities of the chambers were 250 lux (light) and 0 lux (black). In the beginning, the subject mouse was placed in the dark chamber and allowed to move freely for $5 \mathrm{~min}$. The apparatus was thoroughly cleaned with 70\% ethanol for each test.

\section{Whole-cell patch-clamp recordings}

Male POMC-eGFP and AgRP/NPY-hrGFP mice (12 13 weeks old) after CON and CRS paradigm were anesthetized with isoflurane and decapitated to remove the brains. The brains were quickly transferred and sectioned in an ice-cold slicing solution (234 $\mathrm{mM}$ sucrose, $2.5 \mathrm{mM} \mathrm{KCl}, 10 \mathrm{mM} \mathrm{MgSO}{ }_{4}, 0.5 \mathrm{mM} \mathrm{CaCl}_{2}, 1.25$ $\mathrm{mM} \mathrm{NaH} \mathrm{PO}_{4}, 24 \mathrm{mM} \mathrm{NaHCO}_{3}, 11 \mathrm{mM} \mathrm{D}$-glucose). Coronal slices $(\sim 300 \mu \mathrm{m})$ were prepared using a vibrating-knife microtome VT1000s (Leica Microsystems, Germany). Slices were stabilized for at least $1 \mathrm{~h}$ in an oxygenated $\left(95 \% \mathrm{O}_{2} / 5 \% \mathrm{CO}_{2}\right)$ incubation 
A

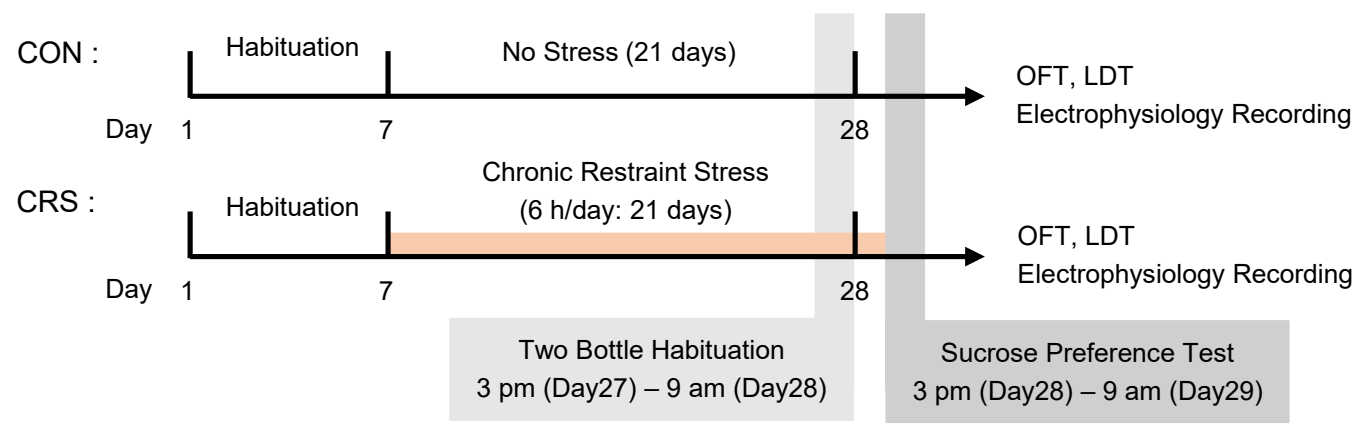

B

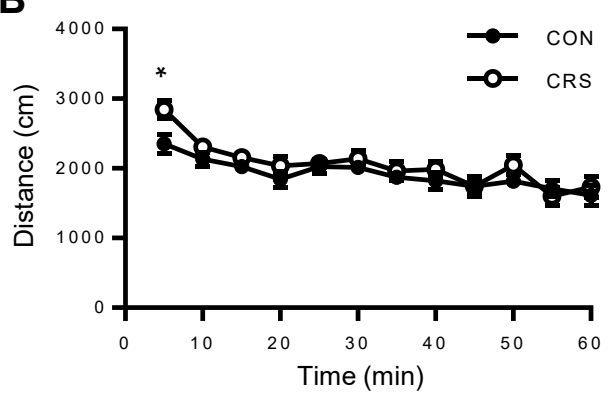

C

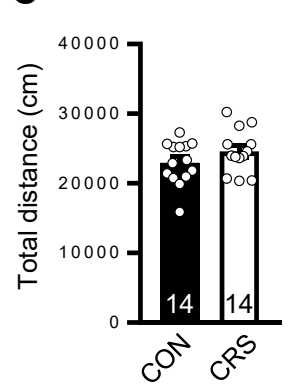

E

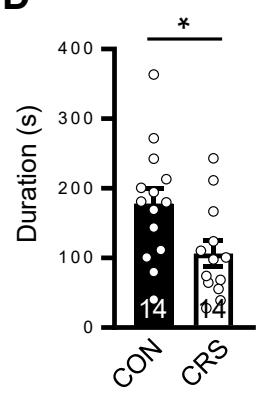

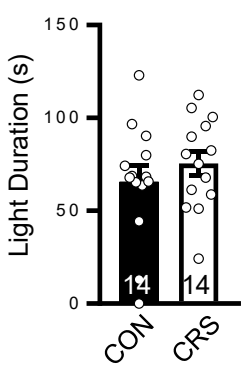

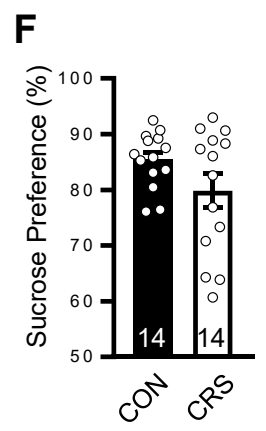

G

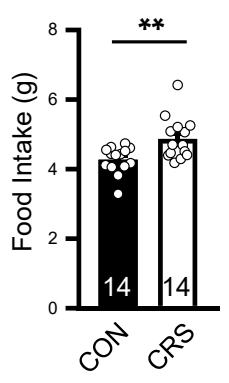

H

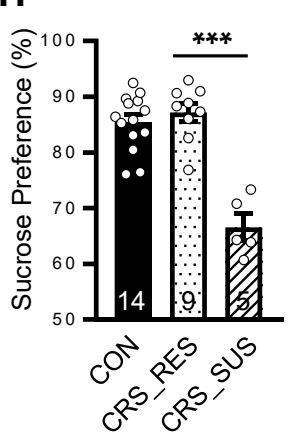

I

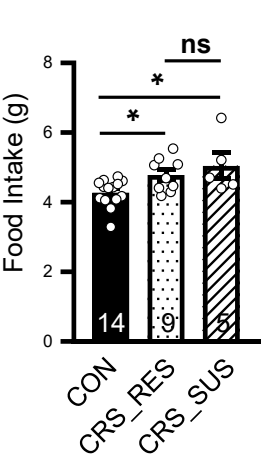

J

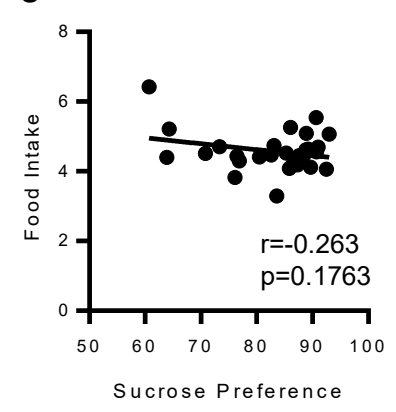

Fig. 1. Chronic restraint stressed mice increased feeding behavior. (A) Timeline of the experimental procedure for control (CON) and chronic restraint stress (CRS). (B) In the open field test, no difference in locomotor behavior was observed at any of the 5 min intervals except in the first 5-min (5-min, $\left.{ }^{*} \mathrm{p}=0.0301\right)$. (C) There was no difference in the total distance moved for $1 \mathrm{~h}$ between groups. (D) CRS mice spent less time in the center zone in the open field, indicating increase in anxiety behavior than $\mathrm{CON}$ mice $\left.{ }^{(* *} \mathrm{p}=0.0066\right)$. (E) In the light dark test, the time spent in light zone was not different between groups. (F) Sucrose preference test was not different between CON and CRS mice. (G) The amount of food intake was increased in CRS mice compared to CON mice $\left.{ }^{* *} \mathrm{p}=0.0047\right)$. (H) CRS groups were divided into two groups, resilient (RES) and susceptible (SUS) mice based on anhedonia behavior. CRS_SUS groups showed significantly decreased sucrose preference than the CON group $\left(\mathrm{F}(2,25)=31.29\right.$; $\left.{ }^{* *} \mathrm{p}<0.0001\right)$. (I) There is no difference of food intake between CRS_SUS and CRS_RES mice $\left(\mathrm{F}(2,25)=5.22 ;{ }^{*} \mathrm{p}=0.0128\right.$; CRS_RES vs CRS_SUS, $\mathrm{p}=0.4466$; CON vs CRS_RES, ${ }^{*} \mathrm{p}=0.0119$; CON vs CRS_SUS, $\left.{ }^{*} \mathrm{p}=0.0121\right)$. (J) Sucrose preference was not correlated with the amount of food intake $(\mathrm{r}=-0.263, \mathrm{p}=0.1763)$. All of the data were from $\operatorname{CON}(\mathrm{n}=14)$ and CRS $(\mathrm{n}=14)$.

solution (124 mM NaCl, $3 \mathrm{mM} \mathrm{KCl,} 6.5 \mathrm{mM} \mathrm{MgSO}_{4}, 1.25 \mathrm{mM}$ $\mathrm{NaH}_{2} \mathrm{PO}_{4}, 26 \mathrm{mM} \mathrm{NaHCO}_{3}, 1 \mathrm{mM} \mathrm{CaCl}, 10 \mathrm{mM}$ glucose). Slices were transferred to the recording chamber and perfused in an oxygenated $\left(95 \% \mathrm{O}_{2} / 5 \% \mathrm{CO}_{2}\right)$ artificial cerebrospinal fluid solution (aCSF: $124 \mathrm{mM} \mathrm{NaCl}, 3 \mathrm{mM} \mathrm{KCl}, 1.3 \mathrm{mM} \mathrm{MgSO}_{4}, 2.4 \mathrm{mM} \mathrm{CaCl}_{2}$, $1.25 \mathrm{mM} \mathrm{NaH}_{2} \mathrm{PO}_{4}, 26 \mathrm{mM} \mathrm{NaHCO}_{3}, 10 \mathrm{mM}$ D-glucose). Individual cells were visualized using an upright Olympus EX51WI
(Olympus, Japan) microscope equipped with an ORCA-R2 camera (Hamamatsu, Japan). POMC and NPY neurons were identified by their green fluorescence and anatomical location in the hypothalamus. Patch electrodes $(2 \sim 5 \mathrm{M} \Omega)$ were prepared with capillary glass (external diameter $1.5 \mathrm{~mm}$ and internal diameter $0.86 \mathrm{~mm}$, Warner Instruments, USA) using a micropipette puller (P-97, Sutter Instrument, CA). Two types of intra-pipette solutions were 
used: a potassium gluconate-based internal solution $(120 \mathrm{mM}$ potassium gluconate, $10 \mathrm{mM} \mathrm{KCl}, 1 \mathrm{mM} \mathrm{MgCl}, 1 \mathrm{mM} \mathrm{CaCl}_{2}, 10$ mM HEPES, 5 mM Mg-ATP, 5 mM EGTA, adjusted to $\mathrm{pH} 7.3$ and osmolarity of $289 \mathrm{mOsm}$ ) for the measurement of neuronal activity and spontaneous excitatory postsynaptic currents (sEPSCs) and cesium-based internal solution (130 mM CsCl, $2 \mathrm{mM} \mathrm{MgCl}$, 10 mM HEPES, 5 mM Mg-ATP, 0.5 mM Na ${ }_{2}$-GFP, 0.1 mM EGTA, $5 \mathrm{mM}$ QX-314, adjusted to $\mathrm{pH} 7.3$ and osmolarity of $282 \mathrm{mOsm}$ ) for the measurement of spontaneous inhibitory postsynaptic currents (sIPSCs). Signals were amplified using MultiClamp 700B (Molecular Devices, USA), and data acquisition was performed using a Digitizer 1440A and Clampex (Molecular Devices, USA). All data analyses were performed using the Clampfit 10.6 (Molecular Devices, USA) and Mini Analysis software (Synaptosoft Inc., USA). Membrane potential and action potential (AP) firing were measured using a whole-cell current-clamp. NPY and POMC neurons after whole-cell clamping were held at $-70 \mathrm{mV}$ by the injection of negative currents and were applied $20 \mathrm{pA}$ ramp pulses at $5 \mathrm{pA} / \mathrm{s}$ to induce AP firing. For AP properties, the threshold was defined as the voltage at which the first derivative of the voltage (dV/dt) exceeded $20 \mathrm{mV} / \mathrm{ms}$ recording by using Clampfit 10.6 software [26]. sEPSCs and sIPSCs were in the voltage-clamp mode with membrane potentials held at $-70 \mathrm{mV}$. In case of sEPSCs to use the potassium gluconate-based internal solution, we calculated the equilibrium potential for chloride using Goldman-Hodgkin-Katz equation, set to $-70 \mathrm{mV}$, and confirmed that sEPSCs were blocked by AMPA and NMDA receptor antagonists $(10 \mu \mathrm{M} C N Q X$ and 50 $\mu \mathrm{M}$ D-AP5). Specifically, spontaneous IPSCs were recorded in the presence of $10 \mu \mathrm{M} \mathrm{CNQX}$ and $50 \mu \mathrm{M}$ D-AP5 to block glutamatergic responses and the blockage was confirmed in the presence of $20 \mu \mathrm{M}$ bicuculline (Bic).

\section{Data analysis}

All results are presented as mean \pm standard error of the mean (SEM). Statistical analyses were performed using GraphPad Prism (GraphPad Software, Inc., CA). The difference between the two groups was analyzed using unpaired t-tests. One-way analyses of variance (ANOVA) followed by Tukey's multiple comparison tests were used for the analysis of the three groups. For the analysis of patch clamp recording files, neurons with series resistance $<30$ $\mathrm{M} \Omega$ were used for statistical analysis. Statistical significance was set at $\mathrm{p}<0.05$.

\section{RESULTS}

\section{Chronic restraint stress induced the increase offood intake}

To investigate the effect of stress on food intake, we monitored the amount of food consumption and conducted the behavioral tests, an open field test (OFT) and light dark box test (LDT), on male mice subjected to restraint stress for 21 days (Fig. 1A). The $5 \mathrm{~min}$ bin of locomotor activity in the OFT was similar between CON and CRS mice, except for during the first 5 min (Fig. 1B). The total distance in the OFT was not altered by chronic stress (Fig. 1C; CON, 22,975 $\pm 816.9, \mathrm{n}=14$; CRS, 24,621 \pm 869.5 , $\mathrm{n}=14$; $\mathrm{p}=0.1794$ ). Additionally, CRS groups showed a decrease in the duration of time spent in the center zone, indicating increased anxiety levels (Fig. 1D; CON, 178.1 $\pm 22.18, \mathrm{n}=14$; CRS, 106.6 \pm 18.13 , $\mathrm{n}=14$; ${ }^{*} \mathrm{p}=0.0204$ ). However, in the LDT to measure anxiety level, the duration of the light zone was not different between the CON and CRS groups (Fig. 1E; CON, 65.81 \pm 8.351 , n=14; CRS, $75.56 \pm 6.59, \mathrm{n}=14 ; \mathrm{p}=0.3682$ ).

We conducted a sucrose preference test for anhedonia to define depressive-like behavior and observed no significant difference between the groups, other than a trend of increased variance level in the CRS group (Fig. 1F; CON, 85.39 $\pm 1.342, n=14$; CRS, $79.83 \pm 3.026, n=14 ; \mathrm{p}=0.1050)$. The amount of food intake after chronic stress was significantly increased in CRS mice (Fig. 1G; CON, 4.28 $\pm 0.1044, \mathrm{n}=14$; CRS, $4.876 \pm 0.162, \mathrm{n}=14$; ${ }^{* *} \mathrm{p}=0.0047$ ). As some studies have shown that mice exposed to chronic stress had anhedonia and anorexic behavior at the same time $[15,16]$, we analyzed the relationship between anhedonia and feeding behavior. Some studies used the anhedonia criteria to divide them into two groups: stress-susceptible (SUS) group, to represent anhedonia, and stress-resilient (RES) group, to represent nonanhedonia [27]. CRS mice were divided into anhedonia groups (CRS_SUS), representing sucrose preference below 75\% which corresponds to two standard deviations from the CON mean [28], and non-anhedonia groups (CRS_RES). CRS_SUS groups which showed significantly decreased sucrose preferences (Fig. 1H; CON, 85.39 $\pm 1.342, \mathrm{n}=14$; CRS_RES, $87.19 \pm 1.635, \mathrm{n}=9$; CRS_SUS, $\left.66.59 \pm 2.351, \mathrm{n}=5 ; \mathrm{F}(2,25)=31.29,{ }^{\star * *} \mathrm{p}<0.0001\right)$. However, feeding behavior was not different between the RES and SUS groups (Fig. 1I; CON, 4.28 \pm 0.1044 , n=14; CRS_RES, $4.78 \pm 0.1585$, n=9; CRS_SUS, $5.05 \pm 0.3696, \mathrm{n}=5$; CRS_RES vs CRS_SUS, $\mathrm{p}=0.4466$ ), and did not correlate with sucrose preference (Fig. 1J). Therefore, we suggest that chronic restraint stress induced weak anxiety and increased feeding behavior independent of anhedonia. This orexigenic behavior in stressed model could be caused by the activation of NPY neurons, one type of first-order neurons to appetite, in the ARC of the hypothalamus. Therefore, we further assessed the activity of NPY neuron in the ARC region. 
A

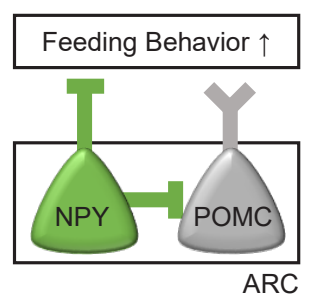

B

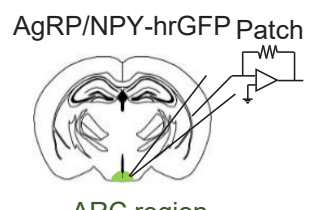

ARC region
Bright Field
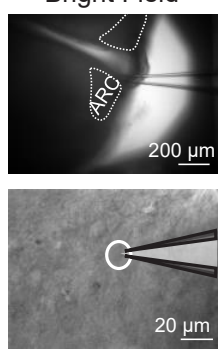

$20 \mu \mathrm{m}$
$\mathbf{F}$

E

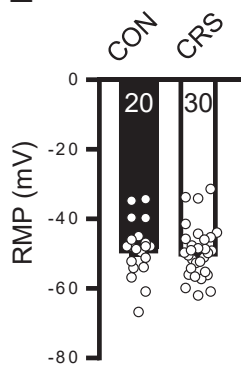

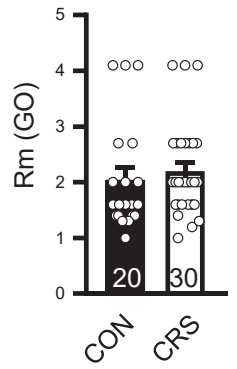

D

$0^{2} c^{\alpha^{5}}$

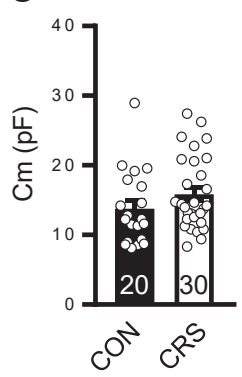

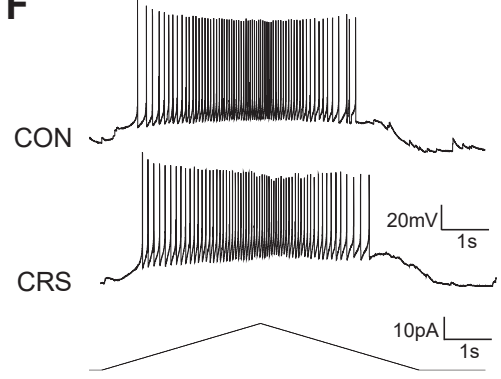

$\mathbf{G}$

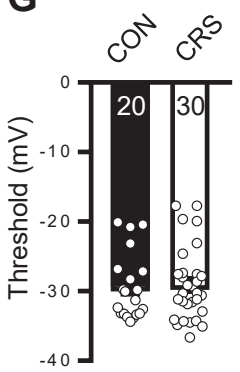

Fig. 2. The intrinsic properties of NPY neurons were not changed by CRS. (A) Schematic diagram for whole cell patch-clamp. (B) Representative images of brain slices from AgRP/NPY-hrGFP mice show that NPY neurons in the ARC region of the hypothalamus are tagged to green fluorescence protein (GFP). (C) The membrane capacitance (Cm) of NPY neurons showed no significant difference. (D) There was no difference in the membrane resistance $(\mathrm{Rm})$ of NPY neurons. (E) No difference in resting membrane potential (RMP). (F) Representative trace of the firing of NPY neurons after the injection of $20 \mathrm{pA}$ ramp currents for detection of action potential (AP) threshold. (G) AP threshold was not changed by CRS. All the data were from CON (20 neurons from 7 mice) and CRS (30 neurons from 12 mice).

\section{The intrinsic excitabilities of NPY neurons were unchanged by chronic stress}

To examine whether stress change the intrinsic excitability of NPY neurons in ARC, we performed the whole-cell patch clamp on GFP-positive neurons at the ARC region in the bottom of the hypothalamus from AgRP/NPY-hrGFP mice (Fig. 2A, 2B) after the stress paradigm (Fig. 1A). The membrane capacitance (Cm) of NPY neurons between groups was not significantly different (Fig. 2C; CON, 13.78 $\pm 1.186, \mathrm{n}=20$; CRS, 15.84 \pm 0.9553 , $\mathrm{n}=30$; $\mathrm{p}=0.1812)$. Additionally, the membrane resistance $(\mathrm{Rm})$ and the resting membrane potential (RMP) were not changed by chronic stress (Fig. 2D; CON, 2.045 \pm 0.22 , n=20; CRS, $2.197 \pm 0.1529$, $n=30$; $\mathrm{p}=0.5616$; Fig. 2E; CON, $-48.54 \pm 1.782$, n=20; CRS, $-49.45 \pm 1.379$, $\mathrm{n}=30 ; \mathrm{p}=0.6821$ ). To determine the membrane potential that initiated an AP, NPY neurons were injected 20pA-ramp stimuli (Fig. 2F). The AP threshold of the NPY neurons was not altered by stress. (Fig. 2G; CON, $-29.36 \pm 1.073, \mathrm{n}=20$; CRS, $-29.1 \pm 0.9469$, $\mathrm{n}=30 ; \mathrm{p}=0.8546$ ). Therefore, chronic stress did not alter the intrinsic excitabilities of the NPY neurons.

\section{Neither sEPSC nor sIPSC in NPY neurons was altered by chronic stress}

Then to investigate synaptic inputs to NPY neurons, we measured spontaneous excitatory and inhibitory postsynaptic currents (sEPSCs and sIPSCs) in NPY neurons (Fig. 3A, 3B, 3H, 3I). The application of NMDA and AMPA receptor blockers (CNQX; 6-cyano-7-nitroquinoxaline-2,3-dione, D-AP5; (2R)amino-5-phosphonovaleric acid) were used to confirm excitatory signals (Fig. 3B, top). No significant difference was observed in the frequency of sEPSCs (Fig. 3C; CON, 0.9397 \pm 0.2143 , $n=12$; CRS, $1.484 \pm 0.2287, \mathrm{n}=19, \mathrm{p}=0.1153)$. Also, the amplitude and area of sEPSCs was unchanged by chronic stress (Fig. 3D; CON, $23.39 \pm 1.746, n=12$; CRS, $22.33 \pm 0.8224, n=19 ; p=0.5437$; Fig. 3E; $\mathrm{CON}, 64.71 \pm 6.251, \mathrm{n}=12 ; \mathrm{CRS}, 57.32 \pm 2.911, \mathrm{n}=19 ; \mathrm{p}=0.2389)$. The rise and decay time of sEPSCs were not different between groups (Fig. 3F; CON, 1.244 $\pm 0.1081, \mathrm{n}=12$; CRS, $1.216 \pm 0.0820$, $\mathrm{n}=19$; $\mathrm{p}=0.8375$; Fig. 3G; CON, 3.244 $\pm 0.3036, \mathrm{n}=12$; CRS, $2.945 \pm 0.1665$, $\mathrm{n}=19 ; \mathrm{p}=0.3563$ ).

Next, we measured sIPSCs in NPY neurons (Fig. 3H, 3I) and confirmed that those currents were GABAergic currents, applying a GABAA receptor blocker, bicuculline (Bic) to block IPSCs (Fig. 3I, top). Chronic restraint stress did not induce changes to the 
A

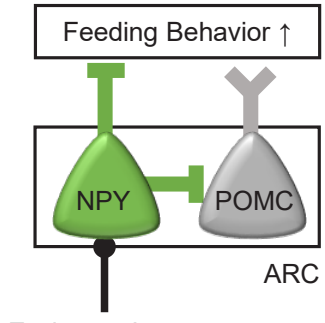

Excitatory Inputs
B

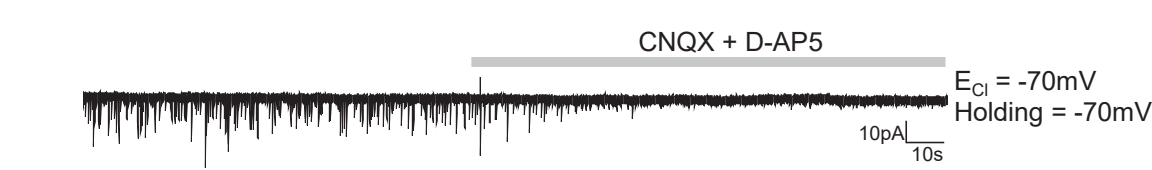

sEPSC
C

(12) (19)

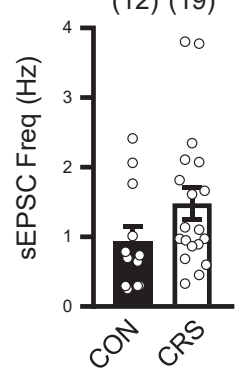

D

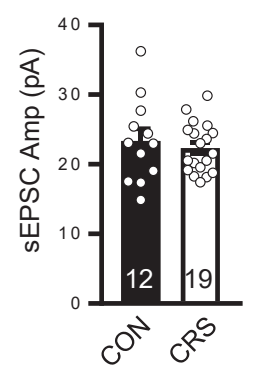

E

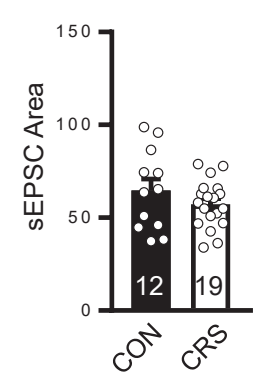

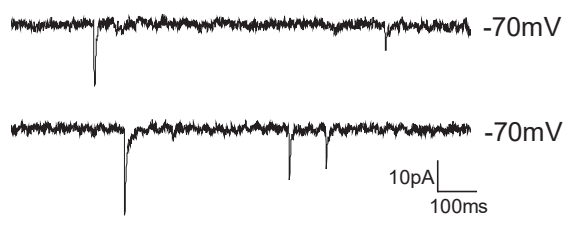

F

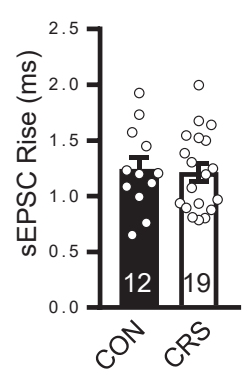

G

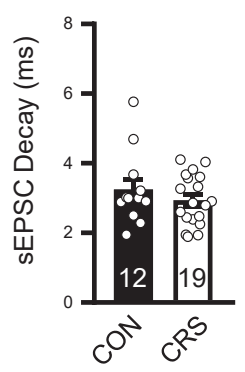

H

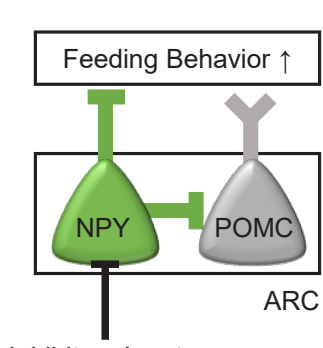

Inhibitory Inputs

I SIPSC
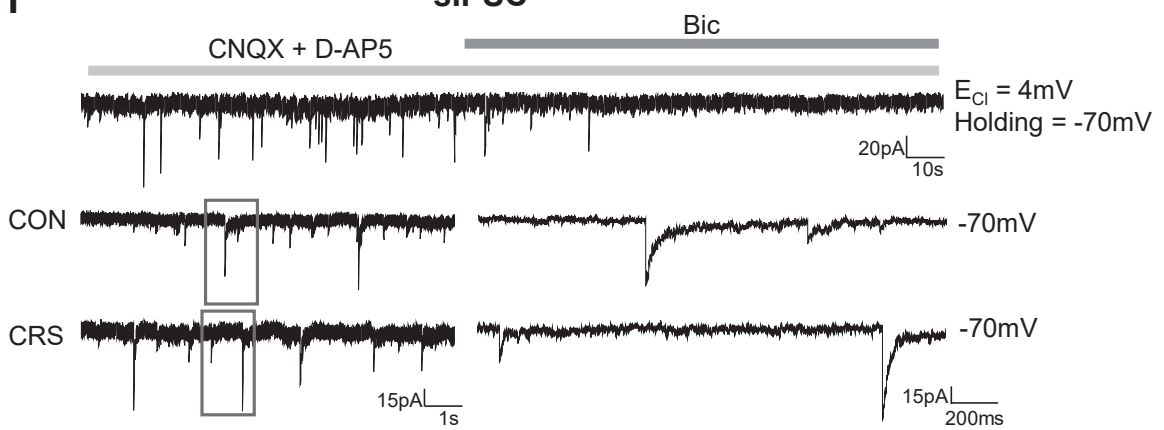

J

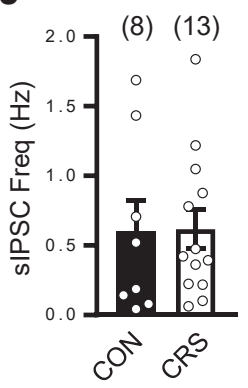

K

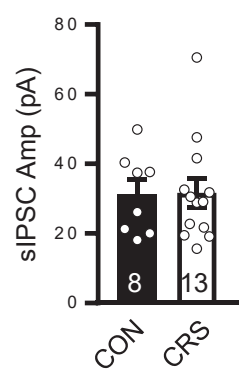

$\mathbf{L}$

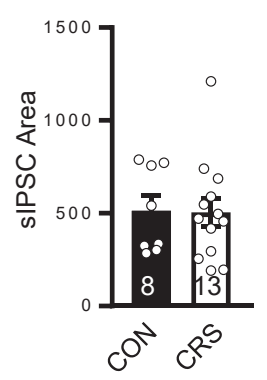

M

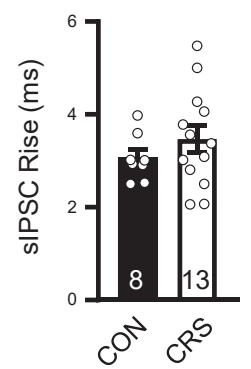

$\mathbf{N}$

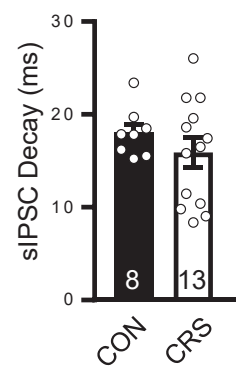

Fig. 3. Restraint stress did not change the excitatory input to NPY neurons. (A) Schematic diagram for whole cell patch-clamp for EPSCs. (B) Representative traces of spontaneous excitatory postsynaptic currents (sEPSC) in NPY neurons from CON and CRS mice. sEPSC was confirmed to block the excitatory signals by bath application of CNQX and APV (top). The gray box in left traces were enlarged to right traces. B. The frequency of sEPSC was not affected by the restraint stress. (C) The amplitude of sEPSC was not changed by restraint stress. (D) The amplitude of sEPSCs. (E) The area of sEPSCs. (F) The rise time of sEPSCs. (G) The decay time of sEPSCs. (H) Schematic diagram for whole cell patch-clamp for spontaneous inhibitory postsynaptic currents (sIPSCs). (I) Representative traces of sIPSCs in POMC neurons from CON and CRS group. The application of bicuculline (Bic) was conducted to confirm sIPSCs (top). Enlarged traces (gray box) represent to right traces. (J) The frequency of sIPSC. (K) The amplitude of sIPSC. (L) The area of sIPSCs. (M) The rise time of sIPSCs. (N) The decay time of sIPSCs. The data for sEPSC were from CON (12 neurons from 7 mice) and CRS (19 neurons from 12 mice). The data for sIPSCs were from CON ( 8 neurons from 3 mice) and CRS ( 13 neurons from 4 mice). 
properties of sIPSCs; the frequency (Fig. 3J; CON, 0.6007 \pm 0.2257 , $\mathrm{n}=8$; CRS, $0.6178 \pm 0.143, \mathrm{n}=13 ; \mathrm{p}=0.9468$ ), the amplitude (Fig. 3K; CON, 31.38 $\pm 4.083, n=8$; CRS, 31.66 $\pm 4.099, n=13 ; p=0.9638)$, the area (Fig. 3L; CON, 513.4 $\pm 80.97, \mathrm{n}=8$; CRS, 504.3 $\pm 76.18, \mathrm{n}=13$; $\mathrm{p}=0.9386$ ), the rise time (Fig. $3 \mathrm{M}$; CON, $3.061 \pm 0.1774, \mathrm{n}=8$; CRS, $3.47 \pm 0.2908, \mathrm{n}=13 ; \mathrm{p}=0.3179$ ), and the decay time (Fig. $3 \mathrm{~N}$; CON, $18.03 \pm 0.9382, n=8$; CRS, $15.9 \pm 1.574, n=13 ; \mathrm{p}=0.3347)$. Therefore, we suggest that NPY neurons are not significantly affected by chronic stress in terms of intrinsic properties and synaptic inputs. Then, we examined POMC neurons in the ARC region, another cell type reported to modulate feeding behavior.

\section{Chronic stress altered the intrinsic excitabilities of POMC neurons}

We examined the intrinsic excitabilities of POMC neurons (Fig. $4 \mathrm{~A}$ ) in POMC-eGFP mice exposed to chronic stress (Fig. 1A). GFP-positive POMC neurons were selected for whole-cell patch clamp (Fig. 4B). The Cm of POMC neurons was not significantly different (Fig. 4C; CON, 20.92 $\pm 1.301, \mathrm{n}=23$; CRS, 22.11 2 2.006, $\mathrm{n}=22)$. The Rm and the RMP had also no difference between groups (Fig. 4D; CON, 1.796 \pm 0.1541 ; CRS, 1.616 \pm 0.167 ; $\mathrm{p}=0.4328$; Fig. 4E; CON, $-52.5 \pm 1.637, \mathrm{n}=23$; CRS, $-52.77 \pm 2.433, \mathrm{n}=22$; $\mathrm{p}=0.9246)$. POMC neurons after the injection of $20 \mathrm{pA}$-ramp stimuli (Fig. 4F) showed that the AP threshold of POMC neurons was increased by chronic stress (Fig. 4G; CON, $-34.07 \pm 0.7218, \mathrm{n}=23$; CRS, $-31.67 \pm 0.8462, n=22 ;{ }^{*} \mathrm{p}=0.0363$ ). Neurons with increased AP threshold could be less reactive to the same stimuli, and then CRS would induce the reduced activity of POMC neurons.

\section{Excitatory inputs, but not inhibitory inputs, to POMC neurons were decreased after chronic stress}

We also investigated the amount of excitatory synaptic inputs to POMC neurons (Fig. 5A, 5B). The frequency of sEPSCs was decreased by chronic stress (Fig. 5C; CON, 1.732 $\pm 0.3455, \mathrm{n}=22$; CRS, $\left.0.7599 \pm 0.1248, \mathrm{n}=19 ;{ }^{*} \mathrm{p}=0.0170\right)$. However, there was no difference in the amplitude of sEPSCs between the CON and CRS groups (Fig. 5D; CON, 18.55 \pm 0.8883 , $\mathrm{n}=22$; CRS, 17.59 \pm 0.8604 , $\mathrm{n}=19 ; \mathrm{p}=0.4411)$. Also, the area, rise time, and decay time of sEPSCs remained unchanged by chronic stress (Fig. 5E; CON, 85.04 $\pm 7.937, \mathrm{n}=22$; CRS, 73.17 $\pm 4.938, \mathrm{n}=19 ; \mathrm{p}=0.2284$; Fig. 5F; CON, 2.171 $\pm 0.1427, n=22 ;$ CRS, $2.077 \pm 0.1573, n=19 ; p=0.6581$; Fig. 5G; CON, 4.555 $\pm 0.3359, \mathrm{n}=22$; CRS, 4.522 $\pm 0.3253, \mathrm{n}=19$; $\mathrm{p}=0.9458$ ). We examined sIPSCs in POMC neurons (Fig. $5 \mathrm{H}$, 5I). The frequency and amplitude of sIPSCs was not changed by chronic stress (Fig. 5J; CON, 1.191 $\pm 0.2568, \mathrm{n}=10$; CRS, $1.096 \pm 0.2511, n=9 ; p=0.7943$, Fig. $5 K ; C O N, 71.96 \pm 5.278, n=10$; CRS, $73.81 \pm 10.89, n=9 ; p=0.8759)$. Also, the area, rise time, and de- cay time of IPSCs were similar between two groups (Fig. 5L; CON, $1127 \pm 86.97, n=10$; CRS, $1277 \pm 153.3, n=9 ; p=0.3921$; Fig. $5 \mathrm{M}$; CON, 3.057 $\pm 0.2147, n=10$; CRS, 3.381 $\pm 0.3825, n=9 ; p=0.4591$; Fig. $5 \mathrm{~N}$; CON, 20.06 \pm 1.062 ; CRS, 21.82 $\pm 1.327, \mathrm{n}=9$; $\mathrm{p}=0.3107$ ). Taken together, chronic stress-induced orexigenic effect might be correlated to the decreased excitatory synaptic inputs and increased AP threshold in POMC neurons.

\section{DISCUSSION}

In the present study, we demonstrated that POMC neurons, but not NPY neurons, in the ARC of the hypothalamus played an important role in the modulation of feeding behavior after exposure to chronic stress. Chronic restraint stress would decrease overall activity of the POMC neurons resulting from an increase in action potential threshold and a decrease in excitatory inputs. This weakens anorexigenic signals, which would disturb the balance between anorexinergic and orexigenic signals. Additionally, these changes in feeding behavior were independent of anhedonia, which is related to the dopaminergic reward system.

In human case studies, patients with major depressive disorders had appetite disturbance in both directions, increase and decrease [29-35]. In the case of depressed adolescents, 58\% of them had a decrease and $28 \%$ had an increase in appetite [29]. Prevalence rates in adults with depression showed that 48\% had decreased and 35\% had increased appetite [29]. In the stress administration experiments, the people increased food intake when exposed to laboratory stressors or self-reported stress $[8,9]$. In contrast to these human studies, most rodent stressed models reported a decrease in food intake, which partially represented the observation in human cases [15-17]. Our chronic restraint models which have increased food intake could be useful to investigate the molecular and circuitry study on the orexigenic effect of stress observed in human patients.

The rodent studies reported that the changes in feeding behavior were related to the hypothalamic POMC neuronal activity or mRNA level $[36,37]$. One study reported that mice exposed to 14-day chronic restraint stress displayed the decrease in food intake for 14 days, caused by the hyperactivity of POMC neurons [37]. They suggested that the projection of POMC to dopamine neurons in the ventral tegmental area (VTA) is important for the regulation of food intake and anhedonia. However, another study showed that a chronic restraint stress model for 15 days decreased food intake for only 7 days after the start of the experiment and recovered [36]. They showed that the decrease in feeding behavior during the first week of chronic stress was caused by an increase in POMC mRNA expression in the hypothalamus, and that the 
A

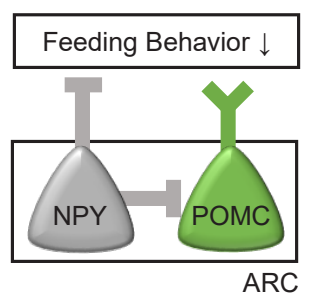

B

D

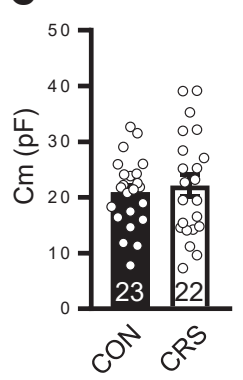

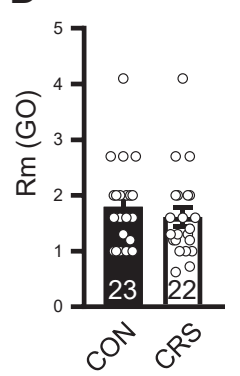
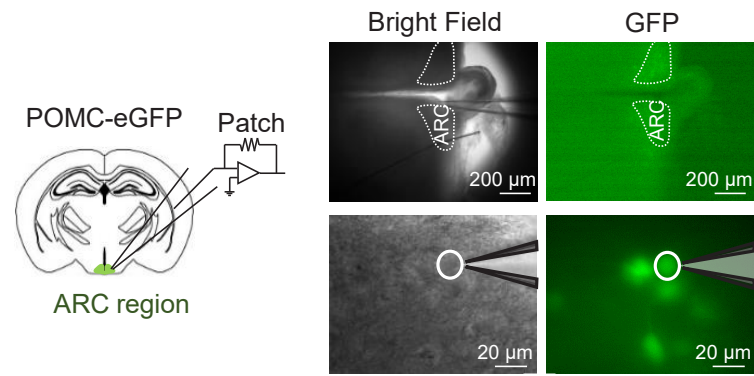

E

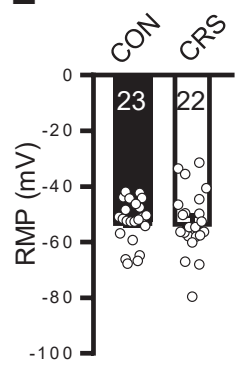

F

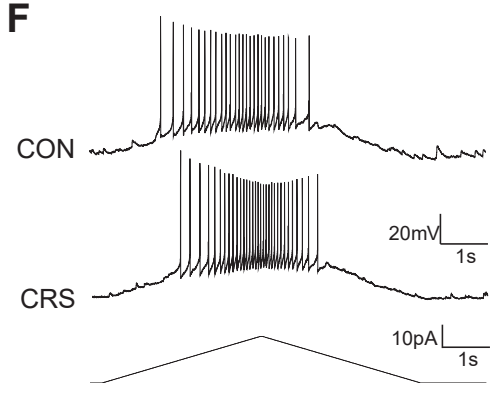

G

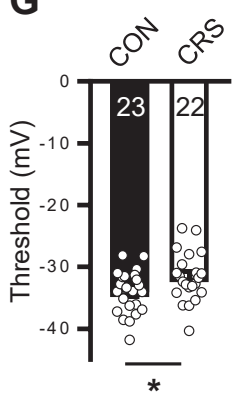

Fig. 4. Chronic stress affected to the change of the intrinsic properties of POMC neurons. (A) Schematic diagram for whole cell patch-clamp. (B) Representative images of brain slices from POMC-eGFP mice indicate GFP-positive POMC neurons in the ARC region of hypothalamus. (C) The Cm of POMC neurons among groups have no difference. (D) The Rm of POMC neurons had no difference. (E) There was no difference in the RMP of POMC neurons. (F) Representative trace of the firing after the injection of $20 \mathrm{pA}$ ramp current to detect threshold of AP in POMC neurons. (G) AP threshold was increased by chronic stress ( $\left.{ }^{*} \mathrm{p}=0.0363\right)$. All the data were from CON (23 neurons from 11 mice) and CRS ( 22 neurons from 11 mice).

recovery in feeding behavior in the next week of chronic stress was induced by the long-lasting decrease in blood leptin levels. In contrast to these previous studies, this study showed that the 21-day chronic restraint stress model increased the amount of food intake independent of anhedonia. The increased food intake occurred parallel with the decreased activity of POMC neurons. It is not yet clear what causes this discrepancy, but the types and duration of stressors might be the factors that differently affect feeding behavioral changes and related neural circuits.

Stress hormones (glucocorticoids) induce stress responses by binding to GR and MR, which mediates the majority of the effects of glucocorticoids and acts as ligand-dependent transcription factors $[38,39]$. The receptors bind directly to DNA via its central DNA binding domain to inverted-repeat GC responsive elements (GREs), which mainly leads to upregulation of diverse gene transcription [39]. Studies showed that chronic stress induced the hyperactivity of HPA axis and increased basal levels of glucocorticoid in serum $[40,41]$. Therefore, there are possibilities that the excess of glucocorticoids after chronic stress could cause the changes in gene expression, leading to several behavioral changes. Indeed, the alteration of basal glucocorticoid levels could change feeding behavior in human and rodents. The patients with Cushing's disease or normal volunteers with glucocorticoid administration showed increased appetites associated with glucocorticoid excess [6]. The chronic administration of corticosterone induced hyperphagia in male mice [42], and decreased expression of serumand glucocorticoid-regulated kinase 1 in POMC neurons [43], which played modulating roles in stress responses and emotional dysfunctions [44-46]. In contrast, adrenalectomy in mice reduced both basal corticosterone levels in serum and food intake [47]. In addition, they showed that synaptic inputs to POMC and NPY neurons were altered by adrenalectomy and recovered by corticosterone administrations [47]. Therefore, it might be expected that changes in synaptic inputs to POMC neurons occurred due to excessive glucocorticoid levels by chronic stress, resulting an increase in food intake. In this study, we focused on the intrinsic and extrinsic properties of POMC and NPY neurons, however, the source of presynaptic glutamatergic projections changed by chronic stress will also be needed. Some researchers have proposed that POMC neurons in the ARC receive projections from microcircuits within the hypothalamus (VMH, PVN, LH, etc.) and other nuclei elsewhere in the brain (septum, hippocampus, pons, etc.) [48-51]. However, it is not fully understood how the electrophysiological functions of these projections to the POMC neurons are related to the regulation of feeding behavior. Therefore, studies on the effects of chronic stress on presynaptic neurons remain to be investigated 
A

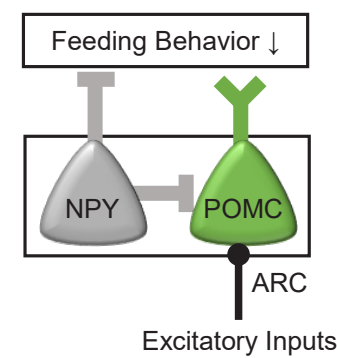

B

sEPSC

C

(22) (19)

D
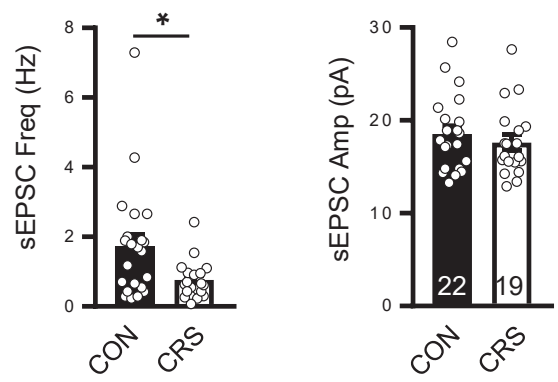

E

$\mathbf{F}$

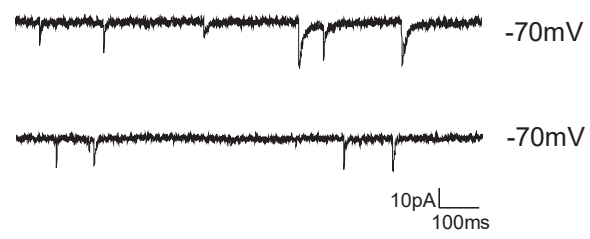

CON

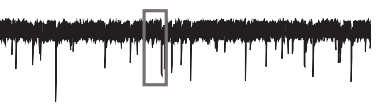

CRS

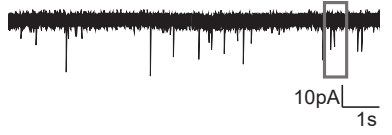

10pAL

G
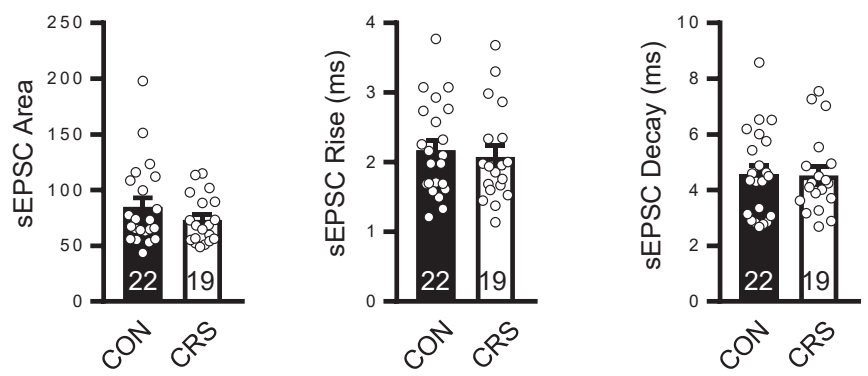

$\mathbf{H}$

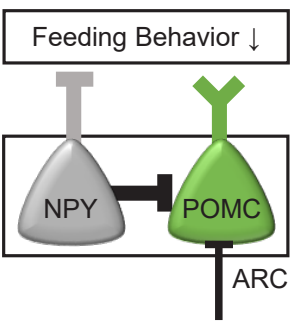

sIPSC
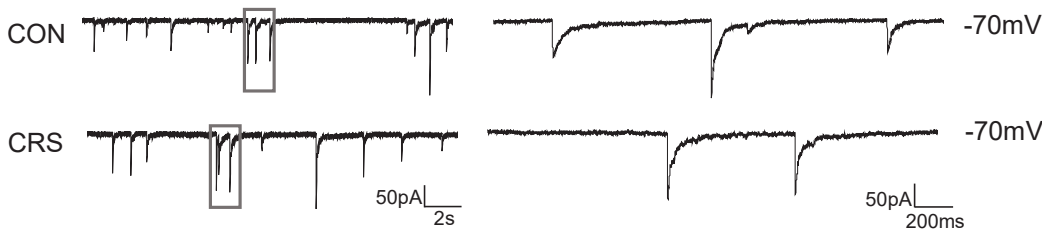

Inhibitory Inputs

$\mathbf{J}$

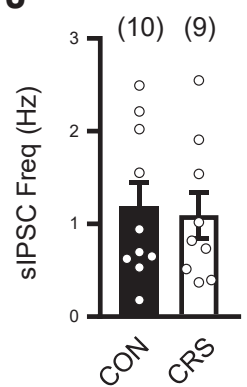

K

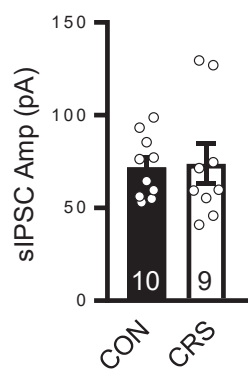

$\mathbf{L}$

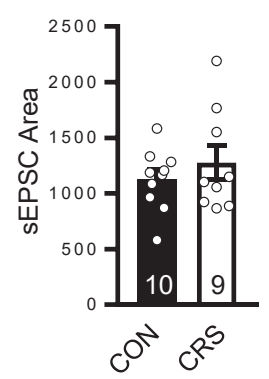

M

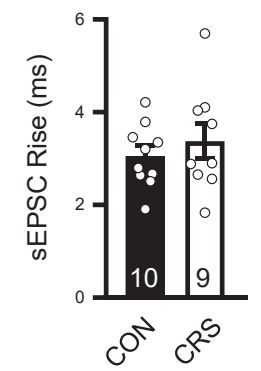

$\mathbf{N}$

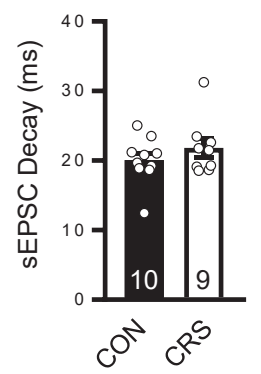

Fig. 5. Chronic stress increased the excitatory input, but not the inhibitory input, to POMC neurons. (A) Schematic diagram for whole cell patch-clamp for EPSCs. (B) Representative traces of sEPSC in POMC neurons from CON and CRS mice. Right traces were enlarging to the gray box in left traces. (C) The frequency of sEPSC in POMC neurons was decreased by chronic stress $\left({ }^{*} \mathrm{p}=0.0229\right)$. (D) The amplitude of $\mathrm{sEPSC}$. (E) The area of sEPSCs. (F) The rise time of sEPSCs. (G) The decay time of sEPSCs. (H) Schematic diagram for whole cell patch-clamp for sIPSCs. (I) Representative traces of sIPSCs in POMC neurons from CON and CRS group. The traces in gray box were enlarged to right traces. (J) The frequency of sIPSC. (K) The amplitude of sIPSC. (L) The area of sIPSCs. (M) The rise time of sIPSCs. (N) The decay time of sIPSCs. The data for sEPSC are from CON ( $22 \mathrm{neurons}$ from 9 mice) and CRS (19 neurons from 10 mice). The data for sIPSCs are from CON (10 neurons from 3 mice) and CRS ( 9 neurons from 3 mice).

to fully understand how the stress modulates feeding behavior.

Additionally, POMC neurons in the ARC with functional heterogeneity, are divided into two types according to their expression of the leptin receptor and serotonin receptors [52]. POMC neurons expressing the leptin receptor have been shown to increase energy expenditure independent of changes in food intake, however, 
those expressing the serotonin $2 \mathrm{C}$ receptors decrease food intake independent of changes in energy expenditure. Consistently, single-cell RNA sequencing data showed that there are three distinct subtypes of POMC neurons, one subtype is enriched leptin receptor and two subtypes are enriched serotonin $2 \mathrm{C}$ receptors [53]. Further study would be needed to understand the function of these heterogenous POMC neurons.

We investigated the intrinsic excitability and synaptic inputs of POMC and NPY neurons, "first-order neurons" to sense the circulating stimuli of hunger and satiety. However, in addition to POMC and NPY neurons in the ARC region, feeding regulation involves various cell types in the hypothalamus and other brain regions. A recent study showed that new GABAergic population in the ARC region, which express prepronociceptin (PNOC) but not POMC and AgRP, also modulates feeding [54]. Optogenetic activation of these PNOC neurons promotes hyperphagia, similar to NPY neurons. In addition, the balance between orexigenic and anorexigenic outputs from "first-order neurons" to "secondorder neurons" in the hypothalamus is important for regulating feeding behavior. Many studies have shown the effects of stress on the PVN of the hypothalamus, second-order neurons [55-57]. Repeated and chronic stress upregulated parvocellular PVN CRH mRNA expression [58] and altered the expression of ionotropic glutamate and GABAA subunits [59]. Therefore, it is necessary to determine the intrinsic and synaptic properties of second-order neurons, such as PVN, LH, DMH, and VMH, especially when receiving signals from POMC neurons of the stressed model.

In summary, we have described that the chronically stressed mice model increased food intake and decreased excitability of POMC neurons, without change in NPY neurons. As our stressed model represented overeating induced by stress in humans, it could be used to identify the mechanisms of stress-induced orexigenic behavior. Future studies on the source of glutamatergic projections to POMC neurons and the effects of stress on these neurocircuits are needed to fully understand the stress-induced orexigenic circuit.

\section{ACKNOWLEDGEMENTS}

This work was supported by the National Research Foundation (NRF) of Korea grant funded by the Korea government (MSIT) (2017M3C7A1023471, 2020R1A4A1019009, and 2021R1A2C3007164), the Korea Health Technology R\&D Project through the Korea Health Industry Development Institute (KHIDI) and Korea Dementia Research Center (KDRC), funded by the Ministry of Health \& Welfare and Ministry of Science and ICT, Republic of Korea (HU20C0066), and the Yonsei Signature Research Cluster Program of 2021-22-0014.

\section{REFERENCES}

1. Herman JP, McKlveen JM, Solomon MB, Carvalho-Netto E, Myers B (2012) Neural regulation of the stress response: glucocorticoid feedback mechanisms. Braz J Med Biol Res 45:292-298.

2. Aronsson M, Fuxe K, Dong Y, Agnati LF, Okret S, Gustafsson JA (1988) Localization of glucocorticoid receptor mRNA in the male rat brain by in situ hybridization. Proc Natl Acad Sci U S A 85:9331-9335.

3. Morimoto M, Morita N, Ozawa H, Yokoyama K, Kawata M (1996) Distribution of glucocorticoid receptor immunoreactivity and mRNA in the rat brain: an immunohistochemical and in situ hybridization study. Neurosci Res 26:235-269.

4. Reul JM, de Kloet ER (1986) Anatomical resolution of two types of corticosterone receptor sites in rat brain with in vitro autoradiography and computerized image analysis. J Steroid Biochem 24:269-272.

5. King BM (1988) Glucocorticoids and hypothalamic obesity. Neurosci Biobehav Rev 12:29-37.

6. Tataranni PA, Larson DE, Snitker S, Young JB, Flatt JP, Ravus$\sin \mathrm{E}$ (1996) Effects of glucocorticoids on energy metabolism and food intake in humans. Am J Physiol 271(2 Pt 1):E317E325.

7. Zakrzewska KE, Cusin I, Stricker-Krongrad A, Boss O, Ricquier D, Jeanrenaud B, Rohner-Jeanrenaud F (1999) Induction of obesity and hyperleptinemia by central glucocorticoid infusion in the rat. Diabetes 48:365-370.

8. Groesz LM, McCoy S, Carl J, Saslow L, Stewart J, Adler N, Laraia B, Epel E (2012) What is eating you? Stress and the drive to eat. Appetite 58:717-721.

9. Schulz S, Laessle RG (2012) Stress-induced laboratory eating behavior in obese women with binge eating disorder. Appetite 58:457-461.

10. Tomiyama AJ, Dallman MF, Epel ES (2011) Comfort food is comforting to those most stressed: evidence of the chronic stress response network in high stress women. Psychoneuroendocrinology 36:1513-1519.

11. Adam TC, Epel ES (2007) Stress, eating and the reward system. Physiol Behav 91:449-458.

12. Chang RS, Cerit H, Hye T, Durham EL, Aizley H, Boukezzi S, Haimovici F, Goldstein JM, Dillon DG, Pizzagalli DA, Holsen LM (2022) Stress-induced alterations in HPA-axis reactivity and mesolimbic reward activation in individuals with emotional eating. Appetite 168:105707.

13. Gecici O, Kuloglu M, Atmaca M, Tezcan AE, Tunckol H, Emül HM, Ustundag B (2005) High serum leptin levels in depres- 
sive disorders with atypical features. Psychiatry Clin Neurosci 59:736-738.

14. Mills JG, Thomas SJ, Larkin TA, Deng C (2020) Overeating and food addiction in major depressive disorder: links to peripheral dopamine. Appetite 148:104586.

15. Harris RB, Zhou J, Youngblood BD, Rybkin II, Smagin GN, Ryan DH (1998) Effect of repeated stress on body weight and body composition of rats fed low- and high-fat diets. Am J Physiol 275:R1928-R1938.

16. Martí O, Martí J, Armario A (1994) Effects of chronic stress on food intake in rats: influence of stressor intensity and duration of daily exposure. Physiol Behav 55:747-753.

17. Fang X, Jiang S, Wang J, Bai Y, Kim CS, Blake D, Weintraub NL, Lei Y, Lu XY (2021) Chronic unpredictable stress induces depression-related behaviors by suppressing AgRP neuron activity. Mol Psychiatry 26:2299-2315.

18. Myers MG Jr, Olson DP (2012) Central nervous system control of metabolism. Nature 491:357-363.

19. Gropp E, Shanabrough M, Borok E, Xu AW, Janoschek R, Buch T, Plum L, Balthasar N, Hampel B, Waisman A, Barsh GS, Horvath TL, Brüning JC (2005) Agouti-related peptideexpressing neurons are mandatory for feeding. Nat Neurosci 8:1289-1291.

20. Balthasar N, Dalgaard LT, Lee CE, Yu J, Funahashi H, Williams T, Ferreira M, Tang V, McGovern RA, Kenny CD, Christiansen LM, Edelstein E, Choi B, Boss O, Aschkenasi C, Zhang CY, Mountjoy K, Kishi T, Elmquist JK, Lowell BB (2005) Divergence of melanocortin pathways in the control of food intake and energy expenditure. Cell 123:493-505.

21. Austin J, Marks D (2009) Hormonal regulators of appetite. Int J Pediatr Endocrinol 2009:141753.

22. Krashes MJ, Koda S, Ye C, Rogan SC, Adams AC, Cusher DS, Maratos-Flier E, Roth BL, Lowell BB (2011) Rapid, reversible activation of AgRP neurons drives feeding behavior in mice. J Clin Invest 121:1424-1428.

23. Waterson MJ, Horvath TL (2015) Neuronal regulation of energy homeostasis: beyond the hypothalamus and feeding. Cell Metab 22:962-970.

24. Betley JN, Cao ZF, Ritola KD, Sternson SM (2013) Parallel, redundant circuit organization for homeostatic control of feeding behavior. Cell 155:1337-1350.

25. Conrad CD, LeDoux JE, Magariños AM, McEwen BS (1999) Repeated restraint stress facilitates fear conditioning independently of causing hippocampal CA3 dendritic atrophy. Behav Neurosci 113:902-913.

26. Sekerli M, Del Negro CA, Lee RH, Butera RJ (2004) Estimating action potential thresholds from neuronal time-series: new metrics and evaluation of methodologies. IEEE Trans Biomed Eng 51:1665-1672.

27. Strekalova T, Spanagel R, Bartsch D, Henn FA, Gass P (2004) Stress-induced anhedonia in mice is associated with deficits in forced swimming and exploration. Neuropsychopharmacology 29:2007-2017.

28. Alves-Dos-Santos L, Resende LS, Chiavegatto S (2020) Susceptibility and resilience to chronic social defeat stress in adolescent male mice: no correlation between social avoidance and sucrose preference. Neurobiol Stress 12:100221.

29. Maxwell MA, Cole DA (2009) Weight change and appetite disturbance as symptoms of adolescent depression: toward an integrative biopsychosocial model. Clin Psychol Rev 29:260273.

30. Friedman RC, Hurt SW, Clarkin JF, Corn R, Aronoff MS (1983) Symptoms of depression among adolescents and young adults. J Affect Disord 5:37-43.

31. Husain MM, Rush AJ, Sackeim HA, Wisniewski SR, McClintock SM, Craven N, Holiner J, Mitchell JR, Balasubramani GK, Hauger R (2005) Age-related characteristics of depression: a preliminary STAR ${ }^{\star} \mathrm{D}$ report. Am J Geriatr Psychiatry 13:852-860.

32. Strober M, Green J, Carlson G (1981) Phenomenology and subtypes of major depressive disorder in adolescence. J Affect Disord 3:281-290.

33. Williamson DE, Birmaher B, Brent DA, Balach L, Dahl RE, Ryan ND (2000) Atypical symptoms of depression in a sample of depressed child and adolescent outpatients. J Am Acad Child Adolesc Psychiatry 39:1253-1259.

34. Yorbik O, Birmaher B, Axelson D, Williamson DE, Ryan ND (2004) Clinical characteristics of depressive symptoms in children and adolescents with major depressive disorder. J Clin Psychiatry 65:1654-1659.

35. Zimmerman M, McGlinchey JB, Young D, Chelminski I (2006) Diagnosing major depressive disorder: II: is there justification for compound symptom criteria? J Nerv Ment Dis 194:235-240.

36. Jeong JY, Lee DH, Kang SS (2013) Effects of chronic restraint stress on body weight, food intake, and hypothalamic gene expressions in mice. Endocrinol Metab (Seoul) 28:288-296.

37. Qu N, He Y, Wang C, Xu P, Yang Y, Cai X, Liu H, Yu K, Pei Z, Hyseni I, Sun Z, Fukuda M, Li Y, Tian Q, Xu Y (2020) A POMC-originated circuit regulates stress-induced hypophagia, depression, and anhedonia. Mol Psychiatry 25:1006-1021.

38. Huang P, Chandra V, Rastinejad F (2010) Structural overview of the nuclear receptor superfamily: insights into physiology and therapeutics. Annu Rev Physiol 72:247-272. 
39. Weikum ER, Knuesel MT, Ortlund EA, Yamamoto KR (2017) Glucocorticoid receptor control of transcription: precision and plasticity via allostery. Nat Rev Mol Cell Biol 18:159-174.

40. Mello AF, Mello MF, Carpenter LL, Price LH (2003) Update on stress and depression: the role of the hypothalamic-pituitary-adrenal (HPA) axis. Braz J Psychiatry 25:231-238.

41. Sachar EJ, Hellman L, Fukushima DK, Gallagher TF (1970) Cortisol production in depressive illness. A clinical and biochemical clarification. Arch Gen Psychiatry 23:289-298.

42. Sefton C, Harno E, Davies A, Small H, Allen TJ, Wray JR, Lawrence CB, Coll AP, White A (2016) Elevated hypothalamic glucocorticoid levels are associated with obesity and hyperphagia in male mice. Endocrinology 157:4257-4265.

43. Deng Y, Xiao Y, Yuan F, Liu Y, Jiang X, Deng J, Fejes-Toth G, Naray-Fejes-Toth A, Chen S, Chen Y, Ying H, Zhai Q, Shu Y, Guo F (2018) SGK1/FOXO3 signaling in hypothalamic POMC neurons mediates glucocorticoid-increased adiposity. Diabetes 67:569-580.

44. Yuen EY, Liu W, Karatsoreos IN, Ren Y, Feng J, McEwen BS, Yan Z (2011) Mechanisms for acute stress-induced enhancement of glutamatergic transmission and working memory. Mol Psychiatry 16:156-170.

45. Anacker C, Cattaneo A, Musaelyan K, Zunszain PA, Horowitz M, Molteni R, Luoni A, Calabrese F, Tansey K, Gennarelli M, Thuret S, Price J, Uher R, Riva MA, Pariante CM (2013) Role for the kinase SGK1 in stress, depression, and glucocorticoid effects on hippocampal neurogenesis. Proc Natl Acad Sci U S A 110:8708-8713.

46. Zhang K, Pan X, Wang F, Ma J, Su G, Dong Y, Yang J, Wu C (2016) Baicalin promotes hippocampal neurogenesis via SGK1- and FKBP5-mediated glucocorticoid receptor phosphorylation in a neuroendocrine mouse model of anxiety/ depression. Sci Rep 6:30951.

47. Gyengesi E, Liu ZW, D'Agostino G, Gan G, Horvath TL, Gao XB, Diano S (2010) Corticosterone regulates synaptic input organization of POMC and NPY/AgRP neurons in adult mice. Endocrinology 151:5395-5402.

48. Garfield AS, Shah BP, Madara JC, Burke LK, Patterson CM, Flak J, Neve RL, Evans ML, Lowell BB, Myers MG Jr, Heisler LK (2014) A parabrachial-hypothalamic cholecystokinin neurocircuit controls counterregulatory responses to hypoglycemia. Cell Metab 20:1030-1037.

49. Sawchenko PE (1983) Central connections of the sensory and motor nuclei of the vagus nerve. J Auton Nerv Syst 9:1326.

50. Sternson SM, Shepherd GM, Friedman JM (2005) Topographic mapping of VMH --> arcuate nucleus microcircuits and their reorganization by fasting. Nat Neurosci 8:13561363.

51. Wang D, He X, Zhao Z, Feng Q, Lin R, Sun Y, Ding T, Xu F, Luo M, Zhan C (2015) Whole-brain mapping of the direct inputs and axonal projections of POMC and AgRP neurons. Front Neuroanat 9:40.

52. Sohn JW, Williams KW (2012) Functional heterogeneity of arcuate nucleus pro-opiomelanocortin neurons: implications for diverging melanocortin pathways. Mol Neurobiol 45:225233.

53. Campbell JN, Macosko EZ, Fenselau H, Pers TH, Lyubetskaya A, Tenen D, Goldman M, Verstegen AM, Resch JM, McCarroll SA, Rosen ED, Lowell BB, Tsai LT (2017) A molecular census of arcuate hypothalamus and median eminence cell types. Nat Neurosci 20:484-496.

54. Jais A, Paeger L, Sotelo-Hitschfeld T, Bremser S, Prinzensteiner M, Klemm P, Mykytiuk V, Widdershooven PJM, Vesting AJ, Grzelka K, Minère M, Cremer AL, Xu J, Korotkova T, Lowell BB, Zeilhofer HU, Backes H, Fenselau H, Wunderlich FT, Kloppenburg P, Brüning JC (2020) PNOCARC neurons promote hyperphagia and obesity upon high-fat-diet feeding. Neuron 106:1009-1025.e10.

55. Herman JP, Flak J, Jankord R (2008) Chronic stress plasticity in the hypothalamic paraventricular nucleus. Prog Brain Res 170:353-364.

56. Herman JP, Tasker JG (2016) Paraventricular hypothalamic mechanisms of chronic stress adaptation. Front Endocrinol (Lausanne) 7:137.

57. Flak JN, Ostrander MM, Tasker JG, Herman JP (2009) Chronic stress-induced neurotransmitter plasticity in the PVN. J Comp Neurol 517:156-165.

58. Herman JP, Adams D, Prewitt C (1995) Regulatory changes in neuroendocrine stress-integrative circuitry produced by a variable stress paradigm. Neuroendocrinology 61:180-190.

59. Hermes ML, Coderre EM, Buijs RM, Renaud LP (1996) GABA and glutamate mediate rapid neurotransmission from suprachiasmatic nucleus to hypothalamic paraventricular nucleus in rat. J Physiol 496(Pt 3):749-757. 